DOI : 10.31357/fapsmph.2003.00588

The work described in this thesis was carried out by me under the supervision of Dr.(Mrs.) Nazeera Salim and a report on this has not been submitted in whole or in part to any University for another Degree/ Diploma.

$31-10-103$

Date

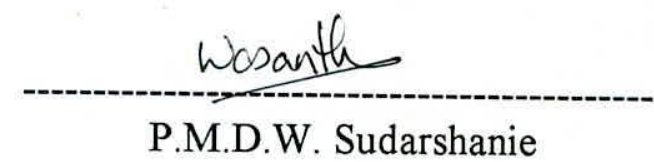


I certify that the above statement made by the candidate is true and that this thesis is suitable for submission to the University for the purpose of evaluation

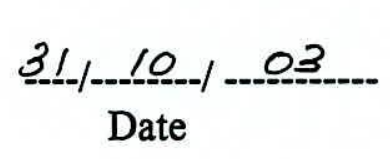
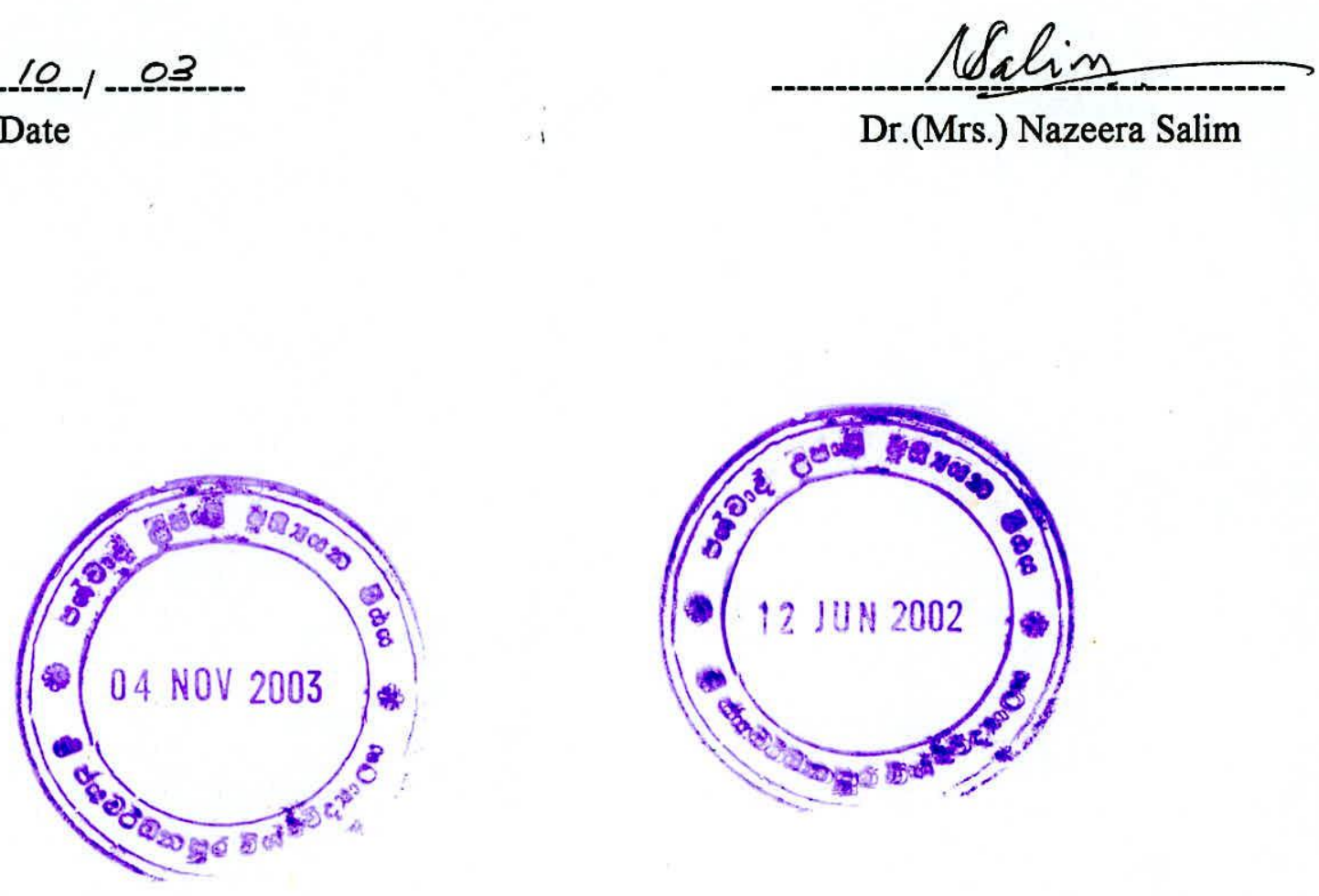


\section{MICROPROPAGATION OF}

OPHIORRHIZA MUNGOS L.

\section{FOR THE PRODUCTION OF}

\section{CAMPTOTHECIN}

By

Pinhene Madinage Deepthi Wasantha Sudarshanie

M.Phil. 2003 


\section{CONTENTS}

Page No.

List of Tables

$v i$

List of Figures

viii

List of Plates

$x$

Acknowledgements $x i$

Abstract xiii

Introduction 1

Chapter 1 - Literature review 3

$1.1 \quad$ Ophiorrhiza mungos L (Dathketiya) 3

1.1.1 Classification of plant 3

1.1.2 Description of the plant 4

1.1.3 Distribution of plant 5

1.1.4 Chemical composition of plant 5

1.1.5 Uses of $O$. mungos 5

1.1.6 Uses of other Ophiorrhiza species 5

$\begin{array}{lll}1.2 & \text { Plant secondary metabolites } & 6\end{array}$

1.2.1 Camptothecin 6

1.2.1.1 Structure of camptothecin and its derivatives

1.2.1.2 Discovery of camptothecin 8

1.2.1.3 Physical properties of camptothecin 9

1.2.1.4 Biological activity of camptothecin and its derivatives 9

1.2.1.5 Other natural sources of camptothecin and its derivatives $\quad 10$ 
1.2.2 Plant tissue culture as an alternative to field grown plants for the production of secondary metabolites

1.2.3 Plant tissue culture used for the production of secondary metabolites of pharmaceutically importance

1.2.4 Yield improvement strategies for the production of plant secondary metabolites by tissue culture

1.3 Callus cultures 20

$\begin{array}{lll}1.4 & \text { Regeneration of plants } & 21\end{array}$

$\begin{array}{lll}1.5 & \text { Root cultures } & 21\end{array}$

\section{Chapter 2 - Materials and Methods}

$2.1 \quad$ Preparation of glassware 23

$2.2 \quad$ Preparation of stock solutions 23

2.2.1 Preparation of stock solutions of inorganic salts and vitamins 23

$\begin{array}{lll}\text { 2.2.2 Preparation of growth regulatorsions } & 24\end{array}$

2.3 Preparation and sterilization of culture media 24

$2.4 \quad$ Selection of plant materials for inoculation 26

2.5 Surface sterilization of explants of O.mungos $L \quad 26$

$\begin{array}{lll}2.6 & \text { Callus cultures } & 29\end{array}$

2.6.1 Initiation of callus from different explants 29

2.6.2 Subculture and maintenance of callus cultures 32

2.6.3 Effect of growth regulators and type of explant 32

on the production of callus

2.6.4 Assessment of growth pattern of callus 33 
2.7.1 Initiation of shoots from callus 34

$\begin{array}{lll}2.7 .2 & \text { Initiation of shoots from axillary buds }\end{array}$

2.7.3 Effect of gibberelic acid on shoot elongation 35

2.7.4 Proliferation of shoots of O.mungos 35

2.7.5 Regeneration of roots in in-vitro propagated 36

shoots of O.mungos

$\begin{array}{lll}2.8 & \text { Root cultures } & 36\end{array}$

$\begin{array}{lll}2.9 & \text { Camptothecin } & 37\end{array}$

2.9.1 Collection of samples for extraction and analysis of 37

camptothecin by HPLC method

2.9.2 Extraction of camptothecin from plant materials 38

and cultures

2.9.3 Determination of camptothecin by HPLC method

$2.10 \quad$ Statistical analysis of data

\section{Chapter 3 - Results}

3.1 Effect of different surface sterilization methods on explants of $O$. mungos $L$. from different types of explants in MS medium from leaf explants in $\mathrm{GB}_{5}$ medium 
3.2.3 Assessment of growth pattern of callus

3.2.3.1 The effect of IBA and kinetin in MS medium on the growth pattern of callus induced from young leaf explants of O.mungos

3.2.3.2 The effect of 2.4.-D and kinetin in MS medium on the growth pattern of callus induced from young leaf explants of O.mungos 50

3.2.4 The effect of different concentrations of 53

growth regulators on the callus size.

3.3.1 Effect of different auxins and cytokinins compositions 55 in MS medium on regeneration of shoots from callus

3.3.2 Effect of different 2.4.-D and kinetin compositions in Woody

Plant Medium (WPM) on regeneration of shoots from callus

3.3.3 Effect of different combinations of IBA + kinetin and

IBA + BAP in MS medium on development of axillary buds.

3.3.4 Effect of gibberelic acid in MS medium on shoot elongation

3.3.5 Effect of different IBA and kinetin combinations in

MS medium on proliferation of shoots Regeneration of roots in in vitro propagated shoots of O.mungos 73

media with $2 \%$ sucrose on 40 days old root cultures of $O$.mungos

3.4.2 Effect of different sucrose levels in different culture media with different concentrations of NAA on 40 days old root cultures of O.mungos 
3.4.3 Effect of incubation period on growth of root cultures in different media containing different sucrose levels

3.5 Determination of camptothecin content in plant organs, callus and root cultures of $O$. mungos

3.5.1 Camptothecin content in field grown plant organs

3.5.2 Camptothecin content in callus induced from young leaf explants of $O$. mungos

3.5.3 Camptothecin content in root cultures

3.5.4 Camptothecin content of in vitro grown plant organs

Chapter 4 - Discussion

Chapter 5 - Conclusions and recommendations

References

Appendices 


\section{LIST OF TABLES}

Page No.

1. Methods of surface sterilization used for young leaf explants of O.mungos

2. Different concentrations of IBA + kinetin used to

initiate the callus from different explants

3. Different concentrations of NAA + BAP used to

initiate the callus from different explants

4. Effect of NAA + BAP combinations on callus induction

from $O$. mungos leaf explants in MS medium

5. Effect of 2.4-D \& BAP combinations on callus induction

from O. mungos leaf explants in MS medium

6. The effect of different concentrations of IBA \& kinetin on the growth

pattern of callus induced from young leaf explants of $O$. mungos

7. The effect of different concentrations of 2.4-D \& kinetin in MS media

on the growth pattern of callus induced from young

leaf explants of $O$. mungos

8. Effect of IBA and kinetin combinations in

MS medium on development of axillary buds.

9. Effect of gibberelic acid in MS medium on shoot elongation 
10. Effect of different combinations of IBA and kinetin in

MS medium on shoot proliferation

11. Effect of different concentrations of NAA and kinetin in

MS half strength medium on regeneration of roots

12. Effect of different sucrose levels in different culture media with different

concentrations of NAA on 40 days old root cultures of $O$.mungos

13. Camptothecin content in field grown plants

14. Camptothecin content in callus

15. Camptothecin content of 40 days old root cultures grown in different

culture media with different concentrations of NAA and $2 \%$ sucrose.

16. Effect of the age of root cultures on production of camptothecin

17. Effect of sucrose on production of camptothecin

in 40 days old root cultures 


\section{LIST OF FIGURES}

Page No

1. Growth of the callus initiated from O.mungos young leaf 49 explants in MS medium with different concentrations of IBA and kinetin

2. Growth of the callus initiated from O.mungos young leaf 52 explants in MS medium with different concentrations of 2.4-D and kinetin

3. The effect of different concentrations of growth regulators on the callus size

4. Effect of 2.4-D and BAP in MS medium on shoot formation

5. Effect of NAA and BAP combinations in MS medium on regeneration of shoots

6. Effect of different concentrations of kinetin in MS medium on regeneration of shoots

7. Effect of 2.4-D and kinetin in WP medium on regeneration of shoots from callus

8. Effect of IBA and BAP compositions in MS medium on development of axillary buds

9. Fresh weights of 40 days old O.mungos root cultures in different culture media with different concentrations of NAA and $2 \%$ sucrose

10. Dry weights of 40 days old O.mungos root cultures in different 79 culture media with different concentrations of NAA \& $2 \%$ sucrose 
11. Fresh and dry weights of roots grown in $\mathrm{GB}_{5}$ medium and $2 \%$ sucrose with the period of time

12. Fresh and dry weights of roots grown in $\mathrm{GB}_{5}$ medium and $3 \%$ sucrose with the period of time

13. Fresh and dry weights of roots grown in $\mathrm{GB}_{5}$ medium and $4 \%$ sucrose with the period of time

14. Fresh and dry weights of roots grown in WPM and $2 \%$ sucrose with the period of time

15. Fresh and dry weights of roots grown in WPM and 3\% sucrose with the period of time

16. Fresh and dry weights of roots grown in WPM and $4 \%$ sucrose with the period of time 


\section{LIST OF PLATES}

Page No.

1. General view of Ophiorrhiza mungos $L$. 3

$\begin{array}{ll}\text { 2. Structure of camptothecin } & 7\end{array}$

$\begin{array}{ll}\text { 3. Structure of } 9 \text { methoxy camptothecin } & 7\end{array}$

4. Structure of 10 methoxy camptothecin 8

5. Structure of 10 hydroxy camptothecin 8

6. Callus initiation from swollen cut ends of leaf explants growing 44 on MS medium with $0.1 \mathrm{mg} / 12.4-\mathrm{D}+0.1 \mathrm{mg} / \mathrm{l}$ kinetin

7. Well developed callus grown on MS medium with $1.0 \mathrm{mg} / \mathrm{l}$

2.4-D + $0.1 \mathrm{mg} / 1$ kinetin, 28 days after incubation

8. Formation of roots from the callus originated from leaf explants grown with NAA $(1.5 \mathrm{mg} / \mathrm{l})$ and kinetin $(0.1 \mathrm{mg} / \mathrm{l})$ in MS medium

9. Thread like callus originated from root explants with NAA $(1.5 \mathrm{mg} / \mathrm{l})$ and kinetin $(0.1 \mathrm{mg} / \mathrm{l})$ in MS medium. Roots grew from the callus

10. Appearance of green colour on callus of O.mungos on MS medium with $0.1 \mathrm{mg} / 12.4 \mathrm{D}+1.0 \mathrm{mg} / \mathrm{l} \mathrm{BAP}$, after 20 days of incubation.

11. Appearance of small outgrowths on callus in MS medium with

$0.1 \mathrm{mg} / 12.4-\mathrm{D}+1.0 \mathrm{mg} / \mathrm{BAP}$, after 70 days of incubation

12. Appearance of small leaves on young shoots on MS medium with

$0.1 \mathrm{mg} / 1$ 2.4-D + $1.0 \mathrm{mg} / \mathrm{l} \mathrm{BAP,}$ after 86 days of incubation

13. Well grown shoots on MS medium with

$0.1 \mathrm{mg} / 1$ 2.4-D + 1.0mg/l BAP, after 115 days of incubation 
14. Small shoots developed on nodes cultured in MS medium with $1.0 \mathrm{mg} / \mathrm{l} \mathrm{IBA}+5.0 \mathrm{mg} / \mathrm{l} \mathrm{BAP}$

15. Fairly developed shoots in MS medium with $1.0 \mathrm{mg} / \mathrm{l} \mathrm{IBA}+5.0 \mathrm{mg} / \mathrm{B} \mathrm{BAP}$

16. Well grown shoots developed from axillary buds on MS medium with $1.0 \mathrm{mg} / \mathrm{lBA}+5.0 \mathrm{mg} / \mathrm{l} \mathrm{BAP}$

17. Shoots in MS medium with $0.1 \mathrm{mg} / 1 \mathrm{GA} 3$, after 4 weeks of incubation 71

18. Rooted plants developed from callus on MS half strength medium 75 with $0.5 \mathrm{mg} / \mathrm{l} \mathrm{NAA}$ after 25 days of incubation

19. Rooted plants developed from axillary buds on MS half strength medium with $0.5 \mathrm{mg} / \mathrm{l} \mathrm{NAA}$ after 25 days of incubation

20. O.mungos roots grown in $\mathrm{GB}_{5}$ medium without NAA in dark.

21. O.mungos roots grown in $\mathrm{GB}_{5}$ medium without NAA in light

(16 hours photoperiod with 240 LUX)

22. O.mungos roots grown in MS medium with $0.5 \mathrm{mg} / \mathrm{l}$ NAA in dark

23. O.mungos roots grown in $\mathrm{GB}_{5}$ medium with $0.5 \mathrm{mg} / \mathrm{l}$ NAA in dark

24. O.mungos roots grown in $\mathrm{GB}_{5}$ medium with $0.5 \mathrm{mg} / \mathrm{l} \mathrm{NAA}$ in light (16 hours photoperiod with 240 LUX of light intensity) 


\section{ACKNOWLEDGMENT}

I sincerely take this opportunity to thank my supervisor Dr. (Mrs.) Nazeera Salim for her assistance, encouragement, psychological support and invaluable guidance given to me at all times to make this project a success. When I was helpless and depressed not being able to finalize this paper due to logistic problems, unless she intervened and gave me the necessary support needed all my hard work would have gone a waste.

I also will take this opportunity to thank Dr. S. S. Ranaweera for his assistance given to me with this regard.

I express my sincere gratitude to Prof. H. G. Nandadasa, Head of the Botany Department and all the faculty members for their assistance given to me during my research work at the University.

I fail to comply with my responsibilities if I do not thank Dr. (Mrs.) Arambewela from Natural Product Section of Industrial Technology Institute who contributed her precious time and knowledge to see this piece of work is a success.

Finally I conclude with special thanks to the staff members of the Faculty of Post Graduate for the kind co-operation given to me at the times of need. 


\begin{abstract}
Ophiorrhiza mungos L. (Dathketiya) is a medicinal plant used in traditional medicine in Sri Lanka and India. This plant produces potent antileukemic and antitumor compounds, camptothecin (CPT) and 10 methoxy camptothecin.
\end{abstract}

Since the propagation of this plant by seeds is slow and viability of seeds is very low, feasibility of propagation in vitro has been studied. Studies were conducted to determine the best explant type for callus culture, to select the suitable nutrient medium and plant growth regulators for callus \& root cultures, regeneration of plants from callus and axillary buds. The camptothecin contents in callus, root, in vitro and in vivo grown plant organs were determined.

Young and mature leaves, stems and petioles from greenhouse grown plants and young leaves and roots from in vitro grown plants were used as explants for callus formation. Different concentrations of auxins, 2.4-dichloro phenoxy acetic acid (2.4-D), Indole butyric acid (IBA) and Naphthalene acetic acid (NAA) in combination with different concentrations of cytokinins, Benzyl aminopurine (BAP) or kinetin in Murashige and Skoog (MS) or Gamborg $\mathrm{B}_{5}\left(\mathrm{~GB}_{5}\right)$ medium were tested. Almost all the growth regulator combinations tested showed $100 \%$ callus formation. Young leaf explants obtained from in vitro grown plants in MS medium with $1.0 \mathrm{mg} / 1$ 2.4-D + $0.1 \mathrm{mg} / \mathrm{l}$ kinetin gave the best callus formation within 10 days. Same explants obtained from greenhouse grown plants also showed better callus formation but it took more time to 
initiate callus than the leaf explants from in vitro grown plants. Callus initiated on $\mathrm{GB}_{5}$ medium was hard and dried out within several days.

For the regeneration of shoots from callus, MS medium with different concentration of auxins (2.4-D and NAA) in combination with different concentrations of BAP, kinetin alone and Woody plant medium (WPM) with different combinations of 2.4-D and BAP were used. Among the tested growth regulator combinations, MS medium with 0.1 $\mathrm{mg} / \mathrm{l} 2.4-\mathrm{D}$ with $1.0 \mathrm{mg} / \mathrm{l} \mathrm{BAP}$ gave mean of 19.3 shoots within 10 weeks and $0.3 \mathrm{mg} / \mathrm{l}$ kinetin gave mean of 15.4 shoots within 8 weeks which were higher than other treatments tested. MS medium with $1.0 \mathrm{mg} / \mathrm{l} \mathrm{IBA}+5.0 \mathrm{mg} / \mathrm{l} \mathrm{BAP}$ gave the highest number of shoots per node.

MS half strength medium containing $0.5 \mathrm{mg} / 1$ NAA with $1.5 \%$ sucrose gave $100 \%$ rooting with long and normal appearance roots while treatment with kinetin resulted short, thick roots. The concentration of $0.1 \mathrm{mg} / \mathrm{l}$ gibberellic acid was suitable for shoot elongation of $O$. mungos.

Eighty days old root cultures grown in WP medium with $2 \%$ sucrose and NAA $(0.5,1.0$ and $1.5 \mathrm{mg} / \mathrm{l})$ gave the highest root yield $(0.53-0.58 \mathrm{~g}$, dry weight) and no significant difference in dry weights were observed with different concentrations of NAA. GB 5 medium with $4 \%$ sucrose also showed very similar results $(0.47-0.53 \mathrm{~g}$ dry weight).

Flowers of field grown plants contained the highest percentage of camptothecin $(0.08 \%)$ compared to roots, leaves and stems. Similar amount of camptothecin was 
produced in 80 day old root cultures grown in WP medium with $2 \%$ sucrose. Although NAA increased the root yield, it inhibited the production of camptothecin.

Forty day old root cultures in $\mathrm{MS}, \mathrm{GB}_{5}$ and WP medium without NAA gave $0.06 \%$ of camptothecin. Callus cultures too produced the similar amount of camptothecin (0.06\%), but it took longer time than above. Among the tested callus, 9 month old callus grown on MS medium with $1.0 \mathrm{mg} / 12.4-\mathrm{D}+0.1 \mathrm{mg} / \mathrm{l}$ kinetin gave the highest amount of camptothecin. 